\title{
Quantitative Metabolomics and Its Application in Metabolic Engineering of Microbial Cell Factories Exemplified by the Baker's Yeast
}

\author{
Mario Klimacek \\ Institute of Biotechnology and Biochemical Engineering, Graz University of Technology \\ Austria
}

\section{Introduction}

The baker's yeast Saccharomyces cerevisiae and its beneficial properties have been recognized very early by human beings. It has been used in the making of alcoholic beverages, bread and cake long before the term biotechnology has been coined. In addition to its great importance in food industry $S$. cerevisiae strains are nowadays applied in many other fields for example in the production of bio-fuels from corn or sugar containing crops, in the biosorption of heavy-metals from sewage, in pharmaceuticals or in the production of precursor compounds for the synthesis of pharmaceuticals or fine chemicals. As a consequence $S$. cerevisiae developed to one of the most important and best investigated microbial cell factories for the industrial (white) biotechnology. Furthermore S. cerevisiae is an important model organism used to elucidate the underlying molecular mechanistic principles that are involved in complex diseases (cancer or diabetes) and metabolic disorders (Castrillo and Oliver 2005; Castrillo and Oliver 2006; Nielsen and Jewett 2008). Other important features of S. cerevisiae that led to its multifaceted applicability in industry and R\&D constitute its GRAS (generally recognized as safe) status and that cells are very easy to cultivate and are readily available.

The physiology of $S$. cerevisiae under various environmental conditions has been investigated intensively in the last 140 years (Racker 1974). The baker's yeast exhibits some very interesting physiological features that render it unique among all other microorganisms. It grows nearly equally fast under aerobic and anaerobic conditions with glucose as the sole carbon source (Nissen et al. 2000a; Visser et al. 1990). Under aerobic conditions and at glucose concentrations above $100 \mathrm{mg} / \mathrm{L}$ biomass formation is accompanied by the production of ethanol as a consequence of an overflow metabolism at the pyruvate node (Crabtree-effect, (Crabtree 1928)). After depletion of glucose the ethanol initially formed by the overflow metabolism is further converted into biomass under aerobic conditions (Diauxie). Under anaerobic conditions about $90 \%$ of glucose carbon is converted into ethanol and $\mathrm{CO}_{2}$. The rate of glucose utilization and the specific ethanol yield is higher under anaerobic conditions as compared to the sugar conversion rate and ethanol yield under aerobic conditions (Pasteur-effect, (Racker 1974)). It can reduce a number of keto-compounds to the corresponding chiral alcohols that represent 
interesting precursors for pharmaceuticals (Csuk 1991). It can grow as a diploid as well as a haploid which highly facilitates genetic manipulation and permits high-throughput genetic engineering.

Considering the enormous early interest in studying and understanding the physiology of $S$. cerevisiae long before modern omics techniques have been developed, it is not very surprising that it was the baker's yeasts genome that was the first within the domain of eukaryotes that was completely sequenced. Genomic and biological information about $S$. cerevisiae molecular biology is comprehensively collected at the Saccharomyces Genome Database (SGD, http://www.yeastgenome.org/). Driven by the knowledge of the complete genomic sequence and by the steadily increasing availability of tools developed for genetic engineering, $S$. cerevisiae became a key work horse and the representative eukaryotic model organism in every modern discipline within the biosciences such as molecular and cell biology, functional genomics, systems biology or metabolic and synthetic engineering. Today's genetic work with $S$. cerevisiae cells is highly alleviated by the presence of a wide spectrum of established yeast molecular biology tool kits and availability of many wild-type and mutant strain (e.g. knock-out strains) collections as well as plasmid collections containing $S$. cerevisiae ORFs, gene deletion markers or promoter sets and many more, offered by commercial sources such as EUROSCARF (http://web.uni-frankfurt.de/fb15/mikro/euroscarf/index.html), Open biosystems (http://www.openbiosystems.com/Products/) or Addgene (http://www. addgene. org/).

The commercial establishment of genetic manipulation techniques paved the way for $S$. cerevisiae to be exploited in the field of metabolic engineering. Various novel recombinant designer strains capable of either selective formation of one desired product or of producing heterologous compounds or endogenous products from new resources (waste or renewable materials) emerged in the last decades. Metabolic engineering efforts based on S. cerevisiae are comprehensively summarized elsewhere and the interested reader is referred to (Bettiga et al. 2010; Nevoigt 2008). A collection of engineered substrate utilization and heterologous or homologous product formation pathways is given in Table 1.

The corresponding underlying engineering principles can be basically broken down into 4 strategies as depicted in Figure 1 panel A-D. Elucidation of the appropriate engineering approach represents the most important step in designing novel cellular properties and targets on the identification of reaction(s) or even entire pathways that are suited for the anticipated metabolic engineering objective. Relevant reaction(s) and associated gene(s) can be extracted by thorough screenings of literature data (US National Library of Medicine (http://www.ncbi.nlm.nih.gov/pubmed), SciFinder (https://scifinder.cas.org/) or Web of Knowledge (http://wokinfo.com/)) and online databases (KEGG the Kyoto Encyclopedia of Genes and Genomes (http://www. genome.jp/kegg/), the enzyme database BRENDA (http://www.brenda-enzymes.org/), or the SIB bioinformatics Resource Portal ExPASy (http://www.expasy.ch/).

To increase the probability of engineering success identified targets can be subjected to in silico modeling by employing mathematical models like restricted flux balance analysis (FBA) based on a genome-scale stoichiometric network to verify their compatibility with the underlying metabolic network (Cvijovic et al. 2010; Selvarajoo et al. 2010). 


\begin{tabular}{|c|c|c|}
\hline Substrate targets & Applications & References \\
\hline Xylose & bio-ethanol & $\begin{array}{l}\text { (Jeffries and Jin 2004; } \\
\text { Petschacher and Nidetzky } \\
\text { 2008; van Maris et al. 2007) }\end{array}$ \\
\hline L-Arabinose & bio-ethanol & (Wisselink et al. 2007) \\
\hline Lactose / whey & bio-ethanol & (Domingues et al. 2010) \\
\hline Galactose & bio-ethanol & (Lee et al. 2010) \\
\hline \multicolumn{3}{|l|}{ Product targets } \\
\hline $\begin{array}{l}\text { Insulin and insulin } \\
\text { precursors }\end{array}$ & pharmaceuticals & (Kjeldsen 2000) \\
\hline Hepatitis B antigen & pharmaceuticals & (Kuroda et al. 1993) \\
\hline Cyanophycin & biopolymer & (Steinle et al. 2009) \\
\hline Organic acids & chemical building blocks & $\begin{array}{l}\text { (Abbott et al. 2009; Ishida et } \\
\text { al. 2006; Raab et al. 2010) }\end{array}$ \\
\hline n-Butanol & bio-fuel & (Steen et al. 2008) \\
\hline Sesquiterpenes & pharmaceuticals and food & $\begin{array}{l}\text { (Asadollahi et al. 2010; } \\
\text { Jackson et al. 2003) }\end{array}$ \\
\hline Carotenoids & pharmaceuticals and food & (Ukibe et al. 2009) \\
\hline Diterpenoids & pharmaceutical industry & (Dejong et al. 2006) \\
\hline Triterpenes & pharmaceutical industry & (Madsen et al. 2011) \\
\hline Polyketides & pharmaceutical industry & (Mutka et al. 2006) \\
\hline $\begin{array}{l}\text { Five-carbon sugars / } \\
\text { alcohols }\end{array}$ & food ingredients & (Toivari et al. 2007) \\
\hline Ethylene & synthetic polymers & (Pirkov et al. 2008) \\
\hline Flavonoids, stilbenoids & pharmaceuticals and food & (Trantas et al. 2009) \\
\hline $\mathrm{SO}_{2}$ & beer flavor stability & (Yoshida et al. 2008) \\
\hline Ethanol & bio-fuel & (Nissen et al. 2000b) \\
\hline
\end{tabular}

Table 1. Collection of metabolic engineering targets in S. cerevisiae

To unravel reaction(s) or pathways instead that would compromise substrate conversion and/or production of a desired product in silico modeling by for example FBA (Bro et al. 2006) or MOMA (minimization of metabolic adjustment) (Asadollahi et al. 2009) have been applied and produced potential candidate reactions which otherwise would have been often overlooked (Cvijovic et al. 2010). The open-source software platform OptFlux developed especially for in silico driven metabolic engineering is available at http:/ / www.optflux.org/ (Rocha et al.).

Metabolic integration of a novel pathway is selected when the utilization of a new substrate (Fig. $1 \mathrm{~A}$ ) or synthesis of a new product is intended (Fig. $1 \mathrm{~B}$ ). New in this context means that the original, not engineered, cells are genetically not programmed to perform these reactions. Formation of an undesired side-product (Fig. $1 \mathrm{C}$ ) can be attributed to a split in carbon flux at the related node $(C)$ into a productive $(C \rightarrow P)$ and undesired flux $(C \rightarrow D)$. Reasons for such flux partition compromising efficient production of the product $(\mathrm{P})$ can be often traced back to the presence of an enzyme or differently regulated isoenzyme competing for the same substrate $S$ or a promiscuous enzyme that in addition to the desired substrate is also active with other substrates (Fig. 1 D). 


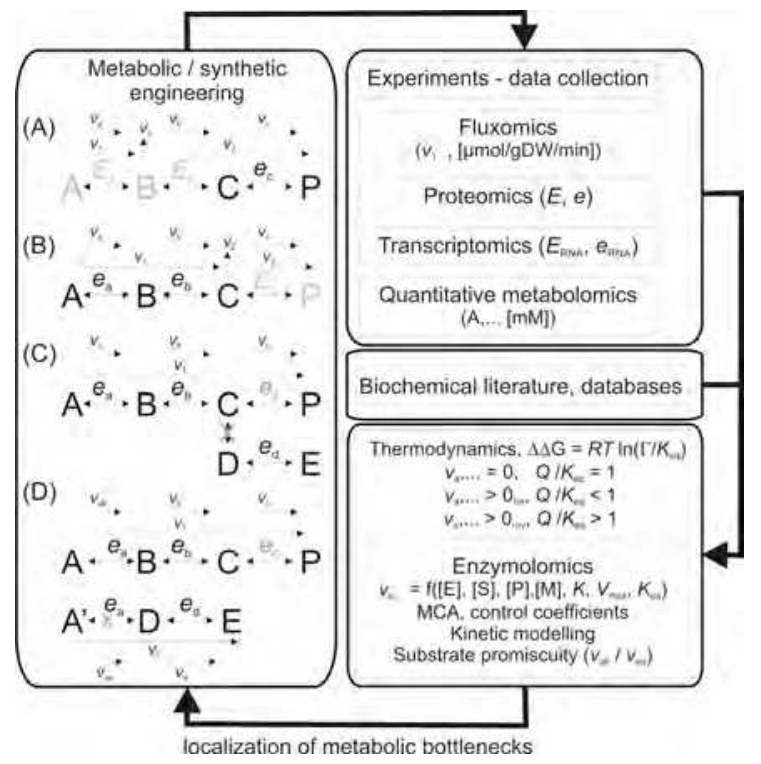

Fig. 1. Typical metabolic engineering principles based on rational design (panels A - D) are linked to a suggested experimental work-flow to unravel limiting metabolic sites. Panels A$D$ refer to enabling of substrate utilization (A) or product formation (B), preventing side product formation by deletion and/or overexpression of an endogenous enzyme (C), increasing selectivity of a substrate promiscuous enzyme (D); Substrate A, intermediate B, product $P$ and enzymes $E$ new to the network are indicated in grey. Overexpression of an endogenous enzyme is depicted by a grey e. Knock outs are indicated by grey $x^{\prime}$ s. Subscripts of rate constants $v$ given as numbers and small letters refer to fluxes based on stoichiometry (solid arrows) and individual reaction rates of enzymes (dotted arrows), respectively.

Directing the carbon flux towards $\mathrm{P}$ can be afforded by deletion of respective gene(s), overexpression of enzymes participating in the productive branch, or replacing the corresponding activity by a less regulated or more selective one. Furthermore unbalanced carbon usage between reaction partners participating in this pathway and/or in the recycling of, for example cofactors, can result in accumulation and release of a pathway intermediate (Krahulec et al. 2009; Krahulec et al. 2010). In this case fine-tuning of all activities involved based on for example a metabolic control analysis (MCA) or kinetic modeling analysis is required to minimize or even completely prevent by-product accumulation (Parachin et al. 2011).

Aside from rational design stochastic methods based on inverse metabolic engineering have been developed for $S$. cerevisiae to identify key target reactions and associated gene sequences enabling the desired new cellular property (Bailey et al. 2002; Bengtsson et al. 2008; Bro et al. 2005; Hong et al. 2010; Jin et al. 2005; Lee et al. 2010). Differently, methods targeting on the induction of a cellular property, such as growth, increase of substrate conversion rate or enhancing resistance to environmental stress, that is hardly to capture by in silico design because of its highly intricate metabolic relations that have to be satisfied, rely on the cellular adaptability to a certain environmental stress by evolution (Cakar et al. 
2009; Cakar et al. 2005; Garcia Sanchez et al. 2010; Kuyper et al. 2005; Sonderegger and Sauer 2003; Wisselink et al. 2009).

In the course of establishing systems biology various high-throughput omics techniques such as transcriptomics, proteomics, fluxomics and others have been developed with the objective to comprehensively analyze cellular physiology at all molecular levels (DNA, RNA, protein, flux, and metabolite). Data-driven analysis is often exploited to unravel novel interrelations at the various molecular levels or to obtain a more insightful (quantitative) understanding of cellular processes. It is obvious that metabolic engineering can greatly benefit from the integration of omics techniques in the design of improved microbial cell factories (Nielsen and Jewett 2008). The various omics tools have helped to increase understanding about how cells regulate, communicate and adapt to different environmental conditions.

Depending on the metabolic engineering objective the appropriate omics tool or a combination should be selected after due consideration. For example transcriptome analysis provides a holistic image of mRNA molecule pattern and levels but do not tell us anything about metabolic fluxes. Optimization of the flux towards a specific metabolite however represents one of the major goals in metabolic engineering. Metabolic flux analyses based on stoichiometric models or ${ }^{13} \mathrm{C}$-isotopomer analysis (provided that cells can grow under the environmental conditions used) are useful tools in this respect (Nielsen and Jewett 2008). To understand the underlying mechanistic relationships between the flux through a particular pathway and the enzymes forming the pathway, providing the relevant information for strain design, detailed knowledge about enzyme-metabolite interactions are required. Consequently quantitative information about metabolites involved together with detailed knowledge of kinetic properties of participating enzymes is mandatory. Within the omics family metabolomics represents the youngest member. This is basically due to the facts that metabolites vary greatly in their physico-chemical properties (polarity, acidity, reactivity, and stability) and are present in a large dynamic concentration range which make it almost impossible to record the entire metabolome on a single analytical platform. Another challenge represents the generation of reliable and representative metabolite data from biological samples. Cell-wall leakage, instabilities and losses of metabolites throughout the sample work-up, or strong matrix effects in the MS analysis are a few of the many causes impairing metabolite data and as a consequence adulterate molecular mechanistic interpretation. Nevertheless in the last years much progress has been made due to enormous efforts of the yeast research community to overcome these obstacles. Protocols of unbiased sample-work-up and different analytical platforms are available today that can cover more than 100 compounds quantitatively.

This review presents current accepted protocols and techniques that enable acquisition of absolute quantitative metabolite data from $S$. cerevisiae cells. The second part focuses on how quantitative metabolite data can help in the development of improved microbial cell factories.

However, before going into the details some definitions of terms used in metabolome analysis should be reminded (Nielsen 2007). Metabolite profiling targets on the qualitative or semi-quantitative analysis of specified metabolites or groups of metabolites. In contrast in metabolite target analysis selected metabolites are quantified. If the entire metabolome or a fraction of it is addressed (or as many metabolites as possible) qualitatively or quantitatively we speak of metabolomics or quantitative metabolomics. 


\section{Data acquisition for quantitative metabolomics in Saccharomyces cerevisiae}

Determination of unbiased intracellular concentrations of metabolites is without doubt a prerequisite for serious interpretation of cellular properties at the molecular - kinetic level. Unbiased refers here to the physiological state, the sample work-up and preparation for metabolite analysis and metabolite quantification and calculation of intracellular molar concentration. Consequently four experimental tasks that have to be fulfilled can be formulated as follows:

- Harvesting and quenching of cells at a predefined physiological state (representative) and separation from extracellular compounds (exometabolome) without leakage of intracellular metabolites (quantitative)

- Destruction of metabolic activity and complete extraction of metabolites by maintaining the metabolite composition quantitatively unchanged, concentration and if required chemical preparation for metabolite analysis

- High-throughput quantitative analysis by employing the appropriate instrument

- Relation of molar concentrations obtained from quantitative analysis to cell specific parameters such as cell dry weight $(\mu \mathrm{mol} / \mathrm{gCDW})$ or cell number ( $\mu \mathrm{mol} / \mathrm{cell})$ or if absolute molar intracellular concentrations are required to the cell (compartment) volume.

However, before we go into the details and hurdles of each task it should be emphasized here that altering the cellular network by metabolic engineering will always result in a quasi new strain with completely new properties and behaviors. In the worst case the complete sample work-up protocol established for the wild-type strain might not be applicable for the mutant strains. It is therefore strongly recommended that protocols already established for the absolute quantification of metabolites have to be re-assessed and verified for the created strains.

\subsection{Representative harvesting and quantitative quenching}

The concentration of a metabolite in the cell is not directly linked to genes but is determined by its formation and utilization rates. Conversion rates in turn depend on the enzymes associated catalytically with this metabolite and their kinetic parameters with respect to this metabolite as well as effectors (inhibitors, activators). In particular metabolites from catabolic reactions and reactions involved in energy metabolism display high turnover rates. For example for the frequently used metabolite ATP $(\sim 16 \%$ of all reactions present in a genome-scale stoichiometric model of S. cerevisiae involve ATP (Förster et al. 2003)) turnover rates of $\sim 1.5$ $\mathrm{mM} / \mathrm{s}$ were reported (Rizzi et al. 1997). Hence, quenching of metabolic activity within a very short time window is required without altering the metabolomic state of the sample. Another highly desirable feature is that the extracellular environment containing substrates, products, salts and the exometabolome, that can affect subsequent metabolite analysis, is separable from the cells without losing any intracellular metabolites due to disruption of or leakage through the cell wall. Different to for example E. coli the cell wall of $S$. cerevisiae is less leaky and both requirements can be achieved for $S$. cerevisiae cells by spraying a defined volume of cell suspension into an appropriate quenching solution at sufficiently low temperatures. It was 
found that the volume ratio of sample to quenching solution affects the quenching quality and a ratio of at least 1 to 5 was suggested (Canelas et al. 2008a).

Today two methods cold methanol and cold glycerol-saline have achieved wide acceptance within the metabolomics community (Canelas et al. 2008a; Villas-Bôas and Bruheim 2007). See Fig. 2 for details. In addition to the quenching temperature and time or the volume ratio between sample and quenching solution, the time between quenching and separation by centrifugation and the centrifugation time can influence metabolic activity and metabolite leakage significantly. Harvesting by rapid sampling is often coupled to quenching. Rapid sampling is especially important in continuous steady-state cultivations and for pulse-experiments in which changes of intracellular metabolite pools induced by a certain environmental impulse are analyzed at the subsecond time scale. Ingenious devices have been developed in the last years that enable rapid sampling and quenching simultaneously at the millisecond scale. The various manual, semiautomatic and fully automatic rapid sampling techniques and their pros and cons have been comprehensively discussed and the reader is referred to (Reuss et al. 2007; van Gulik 2010; Villas-Bôas 2007a). A disadvantage in this context is that most of these devices are not available on the market and therefore not accessible to the scientific community. Commercial accessibility however would be of great importance in the context of comparability, reproducibility and standardization in quantitative metabolomics studies. In batch cultivations manual transfer of the cell suspension to the quenching solution by using a pipette or a syringe is widely accepted as environmental conditions might not change significantly during the sample transfer (3-6s) (VillasBôas 2007b). These assumptions might hold for anaerobic or microaerobic conditions but should be reconsidered in case of aerobic cultivations for which for example the $\mathrm{O}_{2} / \mathrm{CO}_{2}$ ratio may vary and induces changes (oxygen limitation) in cell metabolism during sampling.

\subsection{Quantitative metabolite extraction}

The next challenge represents the quantitative extraction of all metabolites or at least of those to be of interest without reactivating any metabolic activity, enabling chemical reactions and minimizing metabolite disruption. Metabolic activity and chemical reactions can be controlled by the temperature. The addition of a denaturing (inactivating) agent bears some risks as it might be also reactive with metabolites or provides the environment $(\mathrm{pH})$ for chemical reactions (Villas-Bôas 2007b). Control of metabolite degeneration or reactivity during extraction and in the following process steps represents a complex and difficult task. Furthermore metabolite degeneration is a highly specific process and strongly depends on the metabolite species, extraction solution and extraction parameters $(\mathrm{pH}, \mathrm{T})$. For example the redox cofactors $\mathrm{NAD}^{+}$and $\mathrm{NADP}^{+}$are stable at acid to neutral $\mathrm{pH}$ even at high temperatures $\left(80-90^{\circ} \mathrm{C}\right)$ for 3 minutes (Klimacek et al. 2010). On the contrary their reduced counterparts are highly unstable under acidic conditions with NADPH generally less stable than NADH (Chaykin 1967; Lowry et al. 1961). At high pH where $\mathrm{NAD}(\mathrm{P}) \mathrm{H}$ are stable $\mathrm{NAD}(\mathrm{P})$ in turn destruct rapidly (Lowry et al. 1961). Decomposition can also be catalyzed by phosphate a prominent compound in metabolite extracts (van Eunen et al. 2010) by forming an adduct with NADH across the pyridine group (Alivisatos et al. 1964; Chaykin 1967). 


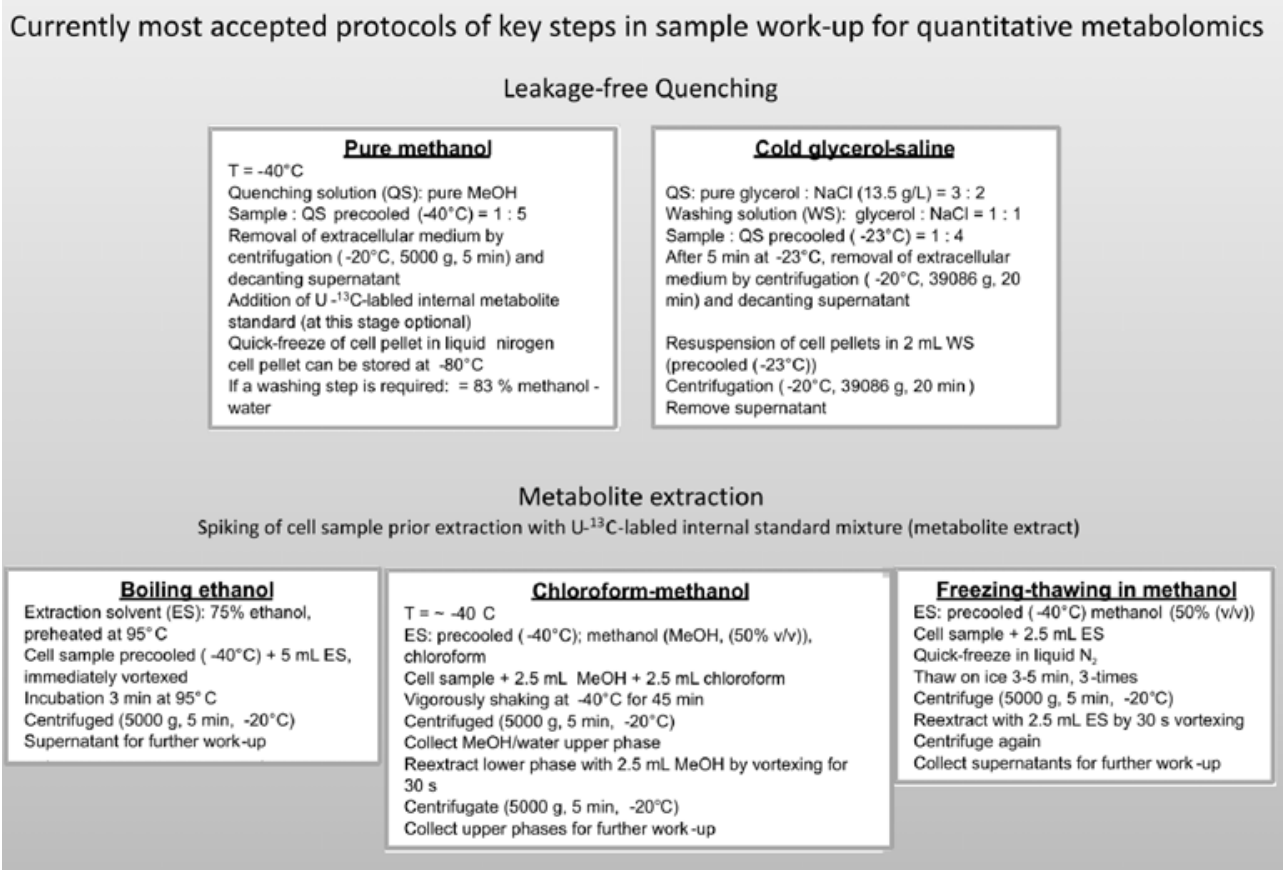

Fig. 2. Collection of state-of-the-art protocols for leakage-free quenching and quantitative extraction. Relevant literature and details can be found in the text.

It is obvious from this example considering just four metabolites that the ideal extraction procedure with which the complete metabolite consortium is extractable without any losses may not exist and calls for a compromise in the selection of conditions used for metabolite extraction. This "inconvenience" however can be circumvented, provided that subsequent metabolite detection is based on mass spectroscopy, by the addition of an aliquot of U-13Clabled internal standard (IS) compounds to the biomass subsequent to quenching or prior to metabolite extraction (Büscher et al. 2009; Canelas et al. 2009; Klimacek et al. 2010; Mashego et al. 2004; Wu et al. 2005). Metabolite losses due to incomplete quantitative work-up of samples can be addressed by application of one selected IS compound. However metabolite specific instabilities, matrix effects, ion suppression, non-linear responses and day-to-day variations can be only identifed and appropriately corrected for by the addition of U-13Clabled IS. A representative mixture of labeled metabolites can be easily prepared from $S$. cerevisiae wild-type and/or mutant cells cultivated in standard mineral medium supplemented with U-13C-labled substrate (glucose, fructose, galactose,...) under the cultivation condition selected and by respective appropriate quenching and extraction procedures. Internal referencing by using an IS displaying a metabolite composition that is representative for the cellular state to be studied should be always taken into account because intracellular metabolite levels can vary considerably in dependence on the cultivation conditions used or on the cellular alterations introduced by pathway engineering (Klimacek et al. 2010). 
Various extraction protocols with respect to extraction solvent (acids, bases, ethanol or methanol, organic solvents), buffered or non-buffered solutions, $\mathrm{pH}$, temperature, etc have been tested (Villas-Bôas 2007b), evaluated and verified for S. cerevisiae cells in terms of metabolite coverage, efficacy and recovery (Klimacek et al. 2010) in the last years (Canelas et al. 2009; Villas-Bôas et al. 2005b). Today three extraction procedures have achieved some acceptance and are likewise used within the yeast research community (see Fig. 2 for details). That is boiling ethanol (BE; pioneered for S. cerevisiae cells by (Gonzalez et al. 1997)), chloroform-methanol (CM; pioneered for $S$. cerevisiae cells by (de Koning and van Dam 1992)) and to some extent freeze-thawing in methanol (FTM; pioneered for S. cerevisiae cells by (Villas-Bôas et al. 2005b) for which however controversial results with respect to its applicability are present in the literature. While (Villas-Bôas et al. 2005b) found extraction performance of FTM sufficient, others (Canelas et al. 2009) concluded that FTM cannot effectively prevent metabolite conversion throughout the extraction process and considered FTM therefore as not appropriate for metabolite extraction. Differences in evaluation criteria and growth conditions were used as a basis to explain the different outcomes. It should be however noted that (Canelas et al. 2009) investigated metabolite extraction performances from $S$. cerevisiae cells grown under two different physiological conditions (glucose limitation and glucose saturation; a bioreactor coupled to a rapid sampling device was used), used identical U-13C-labled compounds as IS and three different analytical methods for quantification of a broad range of different compounds. Quality and metabolite recovery of FTM instead was judged by (Villas-Bôas et al. 2005b) by the application of an IS mixture composed of compounds each a representative for a substance class analyzed. The mixture was added to the quenched cells prior to extraction. Cells were cultivated under aerobic conditions in shake flasks and metabolites were quantified by established GC-MS after metabolite derivatization with methyl chloroformate. In Fig. 2 brief descriptions of respective protocols are compiled. A broad spectrum of compounds covering a wide range of different chemical properties such as acidity, polarity, size and responsiveness can be addressed with either of these extraction protocols. Details with respect to extraction method specific component coverage can be extracted from (Buescher et al. 2010; Büscher et al. 2009; Canelas et al. 2008a; Canelas et al. 2009; Klimacek et al. 2010; Villas-Bôas and Bruheim 2007; Villas-Bôas et al. 2005b).

\subsection{Quantification of intracellular metabolites}

Approximately 600 metabolites are present in S. cerevisiae cells and their concentrations range from sub- $\mu \mathrm{M}$ to $\mathrm{mM}$ (Nielsen 2007). Their levels vary considerably in dependence on the environmental conditions applied or mutation introduced. Hence analysis tools suited for the determination of intracellular metabolites should be able to cover quantitatively as many metabolites as possible in wide concentration ranges.

Early studies that have focused on analyzing intracellular metabolites used enzymatic assays (Ciriacy and Breitenbach 1979; de Koning and van Dam 1992; Gonzalez et al. 1997; Grosz and Stephanopoulos 1990; Kötter and Ciriacy 1993; Theobald et al. 1997) or NMR analysis (den Hollander et al. 1981; Navon et al. 1979; Shanks and Bailey 1988) for quantification of a few compounds present in the cell. To increase the coverage towards a holistic quantitative record of the endometabolome enormous efforts were put on the development of new methods and techniques in the last years. In particular mass 
spectrometry revealed to be excellently suited in this respect and analytics of metabolite targeting switched therefore from an enzyme assay- or NMR-based to a mass spectrometrybased technique. Today three platforms dominate the analytical part of metabolomics. That is mass spectrometric detection in the form of a single, tandem or triple quadrupole or orbitrap mass spectrometer (MS) coupled via an electrospray ionization source (ESI) to a component separation device such as gas chromatography (GC), reverse-phased ion-pairing or anion exchange liquid chromatography (LC) or capillary electrophoresis (CE). Crossplatform comparison with respect to quantitative metabolomics revealed LC as the best suited separation technique for analysis on a single platform in terms of versatility and robustness. It was suggested by the authors that it is best complemented by the use of the GC platform (Büscher et al. 2009). More than 100 metabolites could be successfully quantified by GC-MS ( 100 metabolites, (Villas-Bôas and Bruheim 2007; Villas-Bôas et al. 2003; Villas-Bôas et al. 2005b; Villas-Bôas et al. 2005c)), reverse phase ion pairing LC coupled to a triple quadrupole (138 metabolites, (Buescher et al. 2010)) or an orbitrab mass spec (137 metabolites, (Lu et al. 2010)). Especially the LC-MS platform has been investigated intensively with respect to quantitative metabolite coverage, sensitivity and robustness and revealed to be very suited for the comprehensive analysis of the central carbon metabolism (Buescher et al. 2010; Büscher et al. 2009; Lu et al. 2010). Almost all metabolites involved in glycolysis, pentose phosphate pathway and TCA cycle could be addressed. In addition amino acids and their precursors, redox cofactors, nucleotides, coenzyme A esters and many more can be analyzed in one sample run in approximately half an hour (Buescher et al. 2010; $\mathrm{Lu}$ et al. 2010). Current LC-techniques used in metabolomics are however limited to water soluble analytes (Buescher et al. 2010).

As mentioned above absolute quantification of intracellular metabolites is indispensably linked to the use of $\mathrm{U}^{-13} \mathrm{C}$-labled internal metabolite standards. Consequently the number of compounds to be analyzed doubles which makes data analysis more demanding. Residual amounts of substrates, products and ionic components in the labeled and unlabeled metabolite extracts can significantly alter the elution profile and ionization characteristics of compounds analyzed (Buescher et al. 2010). These so called matrix effects are hardly to predict and are typically experienced as an increase of the base line signal associated with a high signal-to-noise ratio and as shifts in metabolite-specific retention times. Consequently peak-to-peak resolution and base line separation of peaks can become badly affected. Exacerbate and tedious manual peak integration is in these cases required. Alternatively complex often erroneous peak deconvolution algorithms are applied. To reduce matrix effects to a minimum demands preparation of "clean" meaning free of disturbing media compounds - metabolite extracts for both biological samples and IS.

The recommended procedure for internal referencing by identical U-13C-labled compounds involves addition of a defined volume of IS to the biological sample (prior to extraction) and to all analytical standard dilutions (minimum 6 dilutions). A standard mixture containing all the compounds at known concentrations to be analyzed is commonly used. As some metabolites are not very stable it is recommended to store a master mixture containing just the stable compounds and add the sensitive components prior to analysis. Metabolites are quantified by comparing the ratio of ${ }^{12} \mathrm{C}$ - to ${ }^{13} \mathrm{C}$ - signals with the ${ }^{12} \mathrm{C} /{ }^{13} \mathrm{C}$ signals of the representative standard compounds. 


\subsection{Calculation of molar intracellular metabolite concentrations}

The ultimate goal of quantitative metabolomics is the presentation of intracellular metabolite pools in the form of absolute molar concentrations. Only the knowledge of molar concentrations enables reliable integration of metabolome data in thermodynamic analysis, application in MCA based on fundamental enzyme kinetics or kinetic modeling. In the last step of absolute quantification of intracellular metabolite pools, the unbiased molar concentrations of metabolites obtained by the methods described above have to be therefore somehow related to the cell volume. For this reason metabolite concentrations and cell volume are based on the cell dry weight (CDW) producing specific parameters for metabolite concentrations in $\mu \mathrm{mol} / \mathrm{gCDW}\left(=\right.$ [metabolite] ${ }^{*}$ volume of metabolite extract / ([dry cells $]^{*}$ volume of biological sample)) and for the cell volume in $\mathrm{mL} / \mathrm{gCDW}$. By dividing these parameters the intracellular metabolite concentration in $\mathrm{mM}$ is eventually obtained. Hence accurate determination of the CDW and cell volume is mandatory for calculation of reliable intracellular metabolite data and for molecular mechanistic interpretation relying on this data. Different methods can be found in the literature. Briefly, first the physiological state has to be specified at which the CDW should be analyzed. Second an aliquot of cell suspension is separated from the medium by vacuum filtration or centrifugation. The cell pellet is washed with ice-cold water or physiological $\mathrm{NaCl}$ solution to remove residual medium components and subsequently dried at $100-105^{\circ} \mathrm{C}$ until constancy of mass is verified. One should however keep in mind that application of $\mathrm{NaCl}$ can compromise resulting CDW values significantly when low amounts of biomass are addressed. The volume of $S$. cerevisiae cells at a particular physiological state can be determined by applying a Coulter counter analyzer or by microscopic techniques (Lord and Wheals 1981; Tamaki et al. 2005).

The cell volume of the baker's yeast was found to depend on the growth conditions and environmental parameter settings and can vary considerably. For example, the cell volume varies by a factor of 2-3 $\left(16-42 \mu \mathrm{m}^{3}\right)$ with doubling time (Lorincz and Carter 1979; Tyson et al. 1979) and the type of substrate metabolized (Johnston 1977; Tamaki et al. 2005). The lower the doubling time the larger the cells (Tyson et al. 1979). Cells grown on glucose, the most favored carbon source, are larger than those grown on a nonfermentable carbon source (Johnston et al. 1979; Lorincz and Carter 1979; Porro et al. 2003; Tyson et al. 1979). Cells cultured in the presence of ethanol showed an enlarged size (Kubota et al. 2004). In contrast nitrogen starved cells are abnormally small (Johnston 1977). The level of repression/derepression also contribute significantly to the cell size (Mountain and Sudbery 1990). Interestingly therefore that on the basis of the more relevant parameter for quantification the specific cell volume, $S$. cerevisiae cells do not show significant variation with the growth rate (Brauer et al. 2008) and values in the range of $1.5-1.9 \mathrm{~mL} / \mathrm{gCDW}$ can be found in the literature for the strain CEN.PK 113-7D (Canelas et al. 2011; Cipollina et al. 2008; van Eunen et al. 2009). A slightly higher value of $2.38 \mathrm{~mL} / \mathrm{gCDW}$ has been reported for another strain CBS 7336 (ATCC 32167) (Ditzelmüller et al. 1983). We can conclude that although the cell volume is highly sensitive to conditions applied the specific cell volume is rather constant. Nevertheless a 1.6-fold higher specific cell volume results in likewise lower metabolite concentrations which in some cases (e.g. [substrate] $<K_{\mathrm{m}}$ ) may have an influence on the data interpretation. In the light of metabolic engineering it is hard to predict whether this "constant" likewise translates to recombinant cells. For example S. cerevisiae cells 
adapted to high ethanol concentrations displayed an altered cell size (Dinh et al. 2008). Or overexpressing mannitol-1-phosphate dehydrogenase (M1PDH) in S. cerevisiae to produce mannitol from glucose caused a substantial increasing of the size of cells (Costenoble et al. 2003).

As for all eukaryotic organisms S. cerevisiae metabolism is compartmented (cytosol, mitochondrion, vacuoles) which poses a problem for the accurate determination of concentrations of relevant intracellular metabolites. Current techniques for extracting metabolites and isolating organelles do not allow for absolute separation from the cytosol without altering the respective metabolite composition and pattern. Indirect strategies based on metabolic engineering or on fundamental thermodynamic principles have been developed to address this obstacle and gave first preliminary and semi-quantitative insights into the distribution of metabolites between cytosol and mitochondrion.

Functional expression of M1PDH from E. coli in S. cerevisiae was used as indicator reaction to determine the cytosolic free NAD to NADH ratio (Canelas et al. 2008b). M1PDH catalyzes the reversible $\mathrm{NAD}(\mathrm{H})$-dependent interconversion of fructose 6-P (F6P) and mannitol 1-P (M1P). This reaction is directly connected to the central carbon metabolism and represents a dead-end reaction in the metabolism of yeast under the conditions applied in this study. Based on the assumption that the M1PDH reaction is at equilibrium the authors were capable of calculating the NAD/NADH ratio from the equilibrium constant and the intracellular concentrations of F6P and M1P. Data were verified by thermodynamic analysis. The cytosolic ratio of $\mathrm{NAD} / \mathrm{NADH}$ was found to be $\sim 10$-fold higher as compared to the same ratio when based on the whole cell. Under anaerobic conditions however mannitol is formed from M1P implying that this approach is not yet universally applicable (Costenoble et al. 2003).

A different approach based on a network-embedded thermodynamic analysis later termed anNET (Zamboni et al. 2008) was used by (Kümmel et al. 2006) to resolve intracompartmental feasible concentration ranges from cell-averaged metabolome data.

Although these first results are promising there is large open space for the development of novel strategies combined with appropriate experimental techniques that enable precise compartment-specific quantification.

\section{How can metabolic engineering of $S$. cerevisiae benefit from quantitative metabolomics?}

In the typical metabolic engineering approach a bunch of new recombinant strains are designed and created with respect to a particular objective (see Fig. 1) or obtained from evolutionary adaption. Their new phenotypes are tested by fermentation or conversion experiments from which the substrate uptake rate and the product pattern in the form of specific product yields are determined. Results are often applied to FBA for verification. Intracellular enzyme activities of the introduced reactions as well as of those catalyzing reactions relevant for the new phenotype are measured from cell-free extracts. This data set usually provides many valuable details about the production efficiency in terms of conversion rate (how do intracellular activities of target enzymes compare to the conversion rate measured) and product selectivity (identification of side-products and oftentimes the reactions or pathways involved). 
So how do metabolomics and more specifically quantitative metabolomics come into play? As described above the composition of intracellular metabolites together with their levels represent a direct signature of the physiological state of the cells investigated. Comparing metabolite profiles of wild-type and mutant strain(s) was often used to identify target reactions limiting the conversion rate (Hasunuma et al. 2011; Kahar et al. 2011; Klimacek et al. 2010; Kötter and Ciriacy 1993; Wisselink et al. 2010; Zaldivar et al. 2002) or extract the metabolite pattern representative for the new phenotype (Canelas et al. 2008b; Devantier et al. 2005; Ding et al. 2010; Hou et al. 2009; Kamei et al. 2011; MacKenzie et al. 2008; Pereira et al. 2011; Raamsdonk et al. 2001; Ralser et al. 2007; Thorsen et al. 2007; Usaite et al. 2009; Villas-Bôas et al. 2005a; VillasBôas et al. 2005c; Yoshida et al. 2008). Even apparently silent phenotypes of S. cerevisiae single deletion mutants can be uncovered with respect to the underlying mutation based on the developed metabolome (Raamsdonk et al. 2001). The rate however at which a compound's carbon skeleton is channeled through a certain pathway is directly linked to the level of active enzymes present and their affinity to the participating reactants as well as to fundamental thermodynamic laws of the reactions involved. Consequently knowledge about intracellular concentration of metabolites and enzyme activities combined with thermodynamic and enzyme kinetic analysis can provide novel and valuable insights into the kinetic organization of the engineered pathway or even the associated metabolic network which eventually exposes key regulatory or flux limiting sites. Differently to the general holistic approach usually found in systems biology pathway analysis in metabolically engineered cells can be reduced in most cases to the components involved in the new pathway and those connecting this pathway to the central carbon metabolism (Parachin et al. 2011).

\subsection{Thermodynamic pathway analysis}

If we are interested in analyzing a pathway or network of pathways on the basis of thermodynamic rules with the aim to extract pathway or network relevant mechanistic relationships, knowledge of exact quantitative metabolite data of all reactants involved is mandatory. On the contrary we can also check quantitative metabolome data with respect to its thermodynamic consistency (Kümmel et al. 2006) but most importantly we can get first hits of potential candidate reactions for metabolic engineering within a metabolic network without any knowledge about enzyme activity and kinetic parameters. Consider the following reaction

$$
\mathrm{A}+\mathrm{B} \leftarrow \rightarrow \mathrm{C}+\mathrm{D}
$$

The chemical equilibrium constant $\left(K_{\mathrm{eq}}\right)$ associated with this reaction can be defined according to the law of mass action as

$$
K_{\mathrm{eq}}=c_{C}{ }^{\mathrm{eq}} \mathcal{C}_{\mathrm{D}} \mathrm{eq} /\left(c_{\mathrm{A}} \mathrm{eq} c_{\mathrm{B}} \mathrm{eq}\right)
$$

The superscript eq relates to the concentrations $c$ of reactants at the chemical equilibrium. The standard Gibbs energy of a chemical reaction $\left(\Delta_{\mathrm{r}} \mathrm{G}^{0}\right.$, usually given in $\left.\mathrm{J} / \mathrm{mol}\right)$ is related to $K_{\text {eq }}$ by the fundamental relationship

$$
\Delta_{\mathrm{r}} G^{0}=\sum_{i=1}^{N_{\mathrm{s}}} v_{\mathrm{i}} \Delta_{\mathrm{f}} \mathrm{G}_{\mathrm{i}}^{0}=-R T \ln K_{\mathrm{eq}}
$$


in which $v_{\mathrm{i}}$ and $\Delta_{\mathrm{f}} G_{\mathrm{i}}{ }^{0}$ correspond to the stoichiometric coefficient of reactant $i$ and to the standard reaction Gibbs energy of formation of species $i$ at a specified $T, P$ and ionic strength, respectively. $R$ and $T$ denote the general gas constant $(8.314 \mathrm{~J} / \mathrm{mol} / K)$ and absolute temperature in Kelvin $(K)$, respectively. The Gibbs energy of formation of a reactant $i\left(\Delta_{\mathrm{f}} G_{\mathrm{i}}\right)$ is further defined by

$$
\Delta_{\mathrm{f}} G_{\mathrm{i}}=\Delta_{\mathrm{f}} G_{\mathrm{i}}^{0}+R T \ln \left(c_{\mathrm{i}}\right)
$$

$c_{\mathrm{i}}$ in Equation (4) refers to the concentration of reactants involved. The Gibbs energy of a reaction eventually is described by

$$
\Delta_{\mathrm{r}} G=\sum_{i=1}^{N_{\mathrm{s}}} v_{\mathrm{i}} \Delta_{\mathrm{f}} G_{\mathrm{i}}^{0}+R T \sum_{i=1}^{N_{\mathrm{s}}} v_{\mathrm{i}} \ln c_{\mathrm{i}}=\Delta_{r} G^{0}+R T \ln Q
$$

$Q$ in Equation (5) indicates the reaction quotient $c_{C} c_{D} /\left(c_{A} c_{B}\right)$, which is also known under the term "mass action ratio" that is frequently abbreviated by $\Gamma$. Rearranging Equation (4) yields

$$
\Delta_{\mathrm{r}} \mathrm{G}=R T\left\{\ln \left(Q / K_{\mathrm{eq}}\right)\right\}
$$

Now the reaction in Equation (2), reading from the left to the right, takes place freely in the forward direction $\mathrm{A}, \mathrm{B} \rightarrow \mathrm{C}, \mathrm{D}$ at $\Delta_{\mathrm{r}} \mathrm{G}<0\left(K_{\mathrm{eq}}>Q\right)$, is at equilibrium and displays no net flux when $\Delta_{\mathrm{r}} \mathrm{G}=0\left(K_{\mathrm{eq}}=Q\right)$ and needs support by an external driving force when $\Delta_{\mathrm{r}} \mathrm{G}>0\left(K_{\mathrm{eq}}<\right.$ $Q)$. In other words the reverse reaction is favored under these $Q$-conditions implying a net flux in the back direction, $\mathrm{C}+\mathrm{D} \rightarrow \mathrm{A}+\mathrm{B}$. Equation (6) therefore provides a very convenient and important expression that permits immediate assignment of the net flux state of a reaction within a pathway or a large metabolic network provided that $K_{\text {eq }}$ and all reactants participating in the particular reaction are known. The value of $K_{\text {eq }}$ is dependent on the temperature, the ionic strength and the pressure (Alberty 2003). As a consequence only those $K_{\text {eq }} \mathrm{s}$ should be applied that were determined under conditions representative for the cell's physiological state investigated. In particular temperature, ionic strength and $\mathrm{pH}$ are of considerable interest as pressure can be in most cases assumed as a constant. Thereof only the temperature during the cultivation experiment, that is usually $30^{\circ} \mathrm{C}$ for $S$. cerevisiae, is known. Unfortunately most $K_{\mathrm{eq}} \mathrm{s}$ tabulated have been determined at $25^{\circ} \mathrm{C}$. For S. cerevisiae cellular ionic strength and $\mathrm{pH}$ are often assumed to be $0.1 \mathrm{M}$ and 7.0, respectively. This may be sufficient for many thermodynamic network analyses. The validity of these assumptions however should be tested in any event prior pathway or network analysis. Algorithms are available that allow to some extent compensation for ionic strength and temperature.

Equilibrium constants can be determined by three different methods based on either in vitro assay with isolated enzymes, compound-specific standard Gibbs energy of formation (see Equation (3)) or in vivo experiments that combine FBA with quantitative metabolomics.

In case of using an isolated enzyme a reaction assay is designed such that known concentrations of substrate(s) and product(s) are solved in a buffer with defined ionic strength and $\mathrm{pH}$. The reaction is started by the addition of the enzyme and processed at a certain temperature as long as the equilibrium state is reached. Reactant concentrations are then analyzed by appropriate techniques and the apparent $K_{\text {eq }}\left(K_{\text {eq }}^{\prime}\right)$ at a specified $\mathrm{pH}$, ionic 
strength and temperature is calculated with respect to the underlying stoichiometry of the reaction. Values for $K_{\text {eq }}^{\prime}$ are usually applied in the context of network analysis. Importantly all reactants and the enzyme must be of highest purity and must be stable along the time of incubation. The composition of the reaction mixture at the equilibrium must not change in the subsequent component analysis.

When the $\Delta_{\mathrm{f}} \mathrm{G}_{\mathrm{i}}{ }^{0}$ for all reactants participating in the investigated reaction system are known, the respective values for $K_{\text {eq }}$ can be calculated (Alberty 1991). Values for standard Gibbs energies of formation $\Delta_{\mathrm{f}} \mathrm{G}_{\mathrm{i}}{ }^{0}$ have been tabulated for a number of compounds (Alberty 2003). Computer programs are available with which one can calculate transformed standard Gibbs energies of formation $\left(\Delta_{\mathrm{f}} \mathrm{G}_{\mathrm{i}}^{\prime}{ }^{0}\right)$ from $\Delta_{\mathrm{f}} \mathrm{G}_{\mathrm{i}}^{0}$ for a specified $\mathrm{pH}$ and ionic strength (Alberty 2003; Zamboni et al. 2008). In addition all possible dissociation forms of a compound are also lumped into a single reactant in $\Delta_{\mathrm{f}} \mathrm{G}_{\mathrm{i}}{ }^{\prime}$. The respective transformed Gibbs energy of formation for a reactant at a certain concentration $\left(\Delta_{\mathrm{f}} \mathrm{G}_{\mathrm{i}}^{\prime}\right)$ is described by

$$
\Delta_{\mathrm{f}} \mathrm{G}_{\mathrm{i}}^{\prime}=\Delta_{\mathrm{f}} \mathrm{G}_{\mathrm{i}}^{\prime} 0+R T \ln \left(c_{\mathrm{i}}\right)
$$

Applying $\Delta_{\mathrm{f}} \mathrm{G}_{\mathrm{i}}^{\prime}$ and $\Delta_{\mathrm{f}} \mathrm{G}_{\mathrm{i}}{ }^{\prime}$ instead of $\Delta_{\mathrm{f}} \mathrm{G}_{\mathrm{i}}$ and $\Delta_{\mathrm{f}} \mathrm{G}_{\mathrm{i}}{ }^{0}$ in Equations (4) and (5) permit calculation of $K^{\prime}$ eq of a particular reaction. Large-scale thermodynamic studies for which availability of proper $K_{\text {eq }}^{\prime}$ are crucial often bemoan large uncertainties with which current thermodynamic data obtained from enzyme assays or based on Gibbs energies are afflicted and therefore not sufficient for data analysis.

A way to circumvent these obstacles was introduced by (Canelas et al. 2011) who developed a new method to derive apparent equilibrium constants under real in vivo conditions. The basic idea of this work was based upon that the rate $v$ of a certain reaction is directly dependent on the maximal turnover number $V_{\max }$, the kinetic properties $(\beta)$ of the enzyme catalyzing this reaction and on the net flux state of the reaction in relation to the respective equilibrium $\left(1-Q / K_{\text {eq }}^{\prime}\right)$. That is $v=V_{\max } \beta\left(1-Q / K_{\text {eq }}^{\prime}\right)$. S. cerevisiae was cultivated at $30^{\circ} \mathrm{C}$ in chemostats under aerobic conditions and glucose $(7.5 \mathrm{~g} / \mathrm{L})$ as the sole carbon source in standard mineral medium at 32 different dilution rates spanning a wide range of specific growth rates $\left(0.03\right.$ to $\left.0.29 \mathrm{~h}^{-1}\right)$ and as a consequence substrate conversion rates. Extracellular and intracellular metabolites were quantified at each dilution rate. Specific substrate and product fluxes given in $\mathrm{mmol} / \mathrm{gCDW} / \mathrm{h}$ were applied to a FBA based on a stoichiometric model and stoichiometric fluxes $(v)$ for each reaction of the model network were calculated. Mass ratio coefficients $Q$ of 27 network reactions were calculated from quantitative metabolite data at each $v$. From plots of $Q$ vs. $v$ the authors were able to extract values for $K_{\text {eq }}^{\prime}$. It could be shown that $Q$ of reactions operating close to the equilibrium state display a negative linear dependency of $v$. Values of $K^{\prime}{ }_{\text {eq }}$ S representing the thermodynamic equilibrium in the cell were determined by linear extrapolation to the y-axis $\left(v=0\right.$ and $\left.K_{\text {eq }}^{\prime}=Q\right)$ under the assumption that $V_{\max }$ and kinetic properties of enzymes involved are not dependent on $v$. Intracellular $K_{\text {eq }}^{\prime} s$ obtained differed in part significantly (up to a factor of 9) from their in vitro determined counterparts implying that reaction conditions in vivo ( $\mathrm{pH}$ and ionic strength) deviate from that specified in in vitro assays or by the in silico approach. The big advantage of this approach is that in vivo $K_{\text {eq }}^{\prime}$ s can be accurately determined without knowing anything about the intracellular $\mathrm{pH}$ and ionic strength. However only reactions located at or close to the equilibrium state are addressable. 
Combining quantitative metabolomics data with thermodynamic rules on reactions constituting an operating metabolic network enables one to map reactions according to their location with respect to $K_{\text {eq }}^{\prime}$ (Crabtree et al. 1997; Klimacek et al. 2010; Kümmel et al. 2006; Wang et al. 2004). That is close to or far away from equilibrium. A reaction reaches $K_{\text {eq }}^{\prime}$ when the activity of an enzyme catalyzing a reaction downstream is low. On the other hand reactions located far away from $K_{\text {eq }}^{\prime}$ are often catalyzed by enzymes that have regulatory functions in the cell or by flux limiting enzymes representing potential targets for strain improvement (Klimacek et al. 2010). Differently to the relative location of a particular reaction to its equilibrium, the sign (plus or minus) of $\Delta_{\mathrm{r}} G^{\prime}$ or whether $Q>$ or $<K^{\prime}$ eq gives important information about the direction of the reaction or of an entire pathway. Information about flux directions can be readily implemented as further restrictions into a stoichiometric network to increase reliability of flux distributions (Hoppe et al. 2007; Kümmel et al. 2006).

\subsection{Metabolic control analysis based on quantitative metabolomics in metabolic engineering of $S$. cerevisiae}

Identification of those reactions exerting significant control of flux through a particular pathway is crucial to develop strategies for flux improvement. As mentioned above reactions suspected in flux limitation can be elucidated elegantly by thermodynamic analysis. Once identified reactions can be further analyzed with respect to principles of MCA. The concept of MCA was developed and introduced by (Heinrich and Rapoport 1974; Kacser and Burns 1973) and is comprehensively described in (Stephanopoulos et al. 1998). MCA strictly applies only to steady-state conditions. To unravel whether the amount of enzyme or of a reactant participating in the reaction catalyzed by this enzyme contribute to flux limitation through this particular reaction two terms have been defined, namely the flux control coefficient (FCC) and the elasticity coefficient $(\varepsilon)$. The FCC defines the relative change in the steady-state flux resulting from an infinitesimal change in the activity of an enzyme of the pathway divided by the relative change of the enzyme activity, represented by the relationship FCC $=E d J /(J d E)$, in which $E$ and $J$ stand for the concentration or activity of the enzyme and the steady-state flux, respectively. The $\varepsilon$ is intrinsically linked to the inherent enzyme kinetic properties and is defined by the ratio of the relative change in the reaction rate resulted by an infinitesimal change in the metabolite concentration and can be described by $\varepsilon=c_{\mathrm{j}} \delta v_{\mathrm{i}} /\left(v_{\mathrm{i}} \delta c_{\mathrm{j}}\right)$, where $c_{\mathrm{j}}$ and $v_{\mathrm{i}}$ represent the concentration of reactant $j$ and the reaction rate of enzyme $i$. FCC and $\varepsilon$ are related by the flux-control connectivity theorem (Kacser and Burns 1973).

$$
\sum_{i=1}^{L} F C C_{i}^{I} \varepsilon_{c_{j}}^{i}=0
$$

Equation (8) implies that large elasticities - concentration of reactant exerts large control on the enzyme reaction rate - are associated with small FCCs - the overall flux through the pathway is not very dependent on the enzyme activity - and vice versa. Consequently knowledge of either of these coefficient is only required. FCC can be determined by increasing the amount of active enzyme for example by expressing this particular enzyme at different expression levels and measuring the change in flux through the pathway. The level of enzyme present can be judged by determining its specific activity in cell-free extracts. If 
the specific activity $\left(\mu \mathrm{mol} / \mathrm{mg}_{\text {protein }} / \mathrm{min}\right)$ for the isolated enzyme, the cellular protein content $\left(\mathrm{mg}_{\text {protein }} / \mathrm{gCDW}\right)$ and the specific cell volume are known then the molar concentration of this enzyme can be calculated. Enzyme levels can be also determined by proteomics techniques and to some extent extrapolated from transcriptome data. Alternatively suitable antibodies that selectively bind to the target enzymes or fusion of an indicator peptide or protein tag to the enzyme to be analyzed permitting quantification either directly in vivo (GFP) or in vitro after separation of the target enzyme by affinity chromatography (e.g. His-tag, strep-tag) can be used for determining intracellular enzyme concentrations. If rate equations and associated kinetic parameters of all enzymes involved and at least their relative activity levels are known mathematical models can be applied to estimate FCCs and $\varepsilon$ 's. Rate equations based on the steady-state or rapid equilibrium assumption for enzyme catalyzed reactions are comprehensively summarized in (Segel 1993). However kinetic parameters typically used in this approach are determined by in vitro assays and it has been shown that in vitro generated data can significantly differ from those observed in vivo (Aragón and Sánchez 1985; Mauch et al. 2000; Reuss et al. 2007). This discrepancy is most likely due to the incomplete knowledge of the cellular composition and associated enzyme metabolite interactions as well as the difficulty to analyze enzymes under in vivo-like conditions at the lab bench. A promising step forward towards generation of more reliable in vivo-like in vitro enzyme kinetic data was reported recently (van Eunen et al. 2010). The authors suggested to measure enzyme activities in a buffered reaction mixture that simulates the intracellular cellular medium composition of S. cerevisiae.

Using the non-linear lin-log formulation developed for metabolic network analysis by (Visser and Heijnen 2003) FCC and $\varepsilon$ can be estimated without any prior knowledge of enzyme-specific kinetic parameters (Visser and Heijnen 2002). In this approach the reaction rate is a nonlinear function of metabolite concentrations and is proportional to enzyme levels. lin-log kinetics is suited when large perturbations on the systems are analyzed. Furthermore statistical evaluation of parameter estimates is simplified (Wu et al. 2004). Nevertheless it is an approximation that fits to fundamental enzyme-reactant properties only in a certain range of perturbation (Wu et al. 2004).

\subsection{Substrate promiscuous enzymes}

Enzymes that have evolved relaxed or broad substrate specificity are substrate promiscuous (Hult and Berglund 2007). The presence of substrate promiscuous enzymes in a metabolic network considerably aggravates accurate network formulation and analysis if the accurate flux partition between the individual substrates is not known. This problem is further enhanced when the utilized substrates are highly connected within the network by other (substrate promiscuous) reactions. This is possibly best exemplified by the coenzyme promiscuous enzyme xylose reductase (XR) from Candida tenuis (Petschacher et al. 2005). To enable metabolic integration of xylose by $S$. cerevisiae $\mathrm{XR}$ and xylitol dehydrogenase $\mathrm{XDH}$ have to be integrated (Petschacher and Nidetzky 2008). Different to XDH which is strictly dependent on NAD(H) (Nidetzky et al. 2003), XR can oxidize both NADH and NADPH. These coenzymes in turn form the redox state of a cell and are important currency metabolites in all catabolic and anabolic pathways of the cell. Hence, keeping the redox state with respect to anabolism and catabolism balanced is crucial for the cell to stay alive. It was found based on stoichiometric considerations that the NADPH usage of XR is in strong 
correlation with by-product formation in the form of xylitol, the reaction product of $\mathrm{XR}$ and the substrate of $\mathrm{XDH}$ in the subsequent reaction (van Maris et al. 2007). Usage of up to (0$52) \%$ NADPH by XR was compatible with a genome-scale metabolic network (Krahulec et al. 2010). Detailed kinetic analysis from in vitro studies showed that the $X R$ almost exclusively utilizes NADPH in terms of catalytic efficiency $\left(k_{\text {cat }} / K_{\mathrm{m} \text {,coenzyme }}\right)$ and the selectivity parameter $R_{\text {sel }}\left(k_{\text {cat }} /\left(K_{\mathrm{i}, \text { coenzyme }} K_{\mathrm{m}, \text { xylose }}\right)\right)$ which are widely used as marker parameter for coenzyme discrimination. Based on this data even a rough estimation of the coenzyme usage of XR in the cell is not possible. To solve the coenzyme usage riddle of XR we determined intracellular concentrations of NADH and NADPH (Klimacek et al. 2010) and integrated this information together with the relevant kinetic parameters (Petschacher et al. 2005) into the mechanistically appropriate enzyme kinetic rate expression (Banta et al. 2002; Petschacher and Nidetzky 2005). A balanced coenzyme usage perfectly in line with physiology observed was obtained for the XR (Klimacek et al. 2010). Information about the correct flux partition of a particular substrate promiscuous enzyme can be implemented as further restrictions into a stoichiometric network to increase reliability of flux distributions. Furthermore this approach could be successfully applied on a series of wild-type and mutant forms of XR to predict reliably formation of xylitol (Krahulec et al. 2011).

\section{Conclusions}

Quantitative metabolomics is especially suited to help identifying key sites limiting an engineered metabolic route either within the created pathway but also apart from it. Stateof-the-art protocols for sample work-up and LC-MS and GC-MS analysis permit absolute quantification of metabolites from $S$. cerevisiae cells provided that a U-13C-labled IS is applied. Quantitative data in turn are indispensible for reliable pathway and network analysis in the form of a thermodynamic analysis, MCA or kinetic modelling. In combination with other omics techniques it represents a powerful tool to create designer microbial cell factories exposing improved or novel phenotypes.

\section{Acknowledgement}

Financial support from the Austrian Science Fund FWF (J2698) is gratefully acknowledged.

\section{References}

Abbott DA, Zelle RM, Pronk JT, van Maris AJ. 2009. Metabolic engineering of Saccharomyces cerevisiae for production of carboxylic acids: current status and challenges. FEMS Yeast Res 9(8):1123-36.

Alberty RA. 1991. Equilibrium compositions of solutions of biochemical species and heats of biochemical reactions. Proc Natl Acad Sci U S A 88(8):3268-71.

Alberty RA. 2003. Thermodynamics of biochemical reactions. Alberty RA, editor. New Jersey: John Wiley \& Sons, Inc.

Alivisatos SG, Ungar F, Abraham G. 1964. Non-Enzymatic Interactions of Reduced Coenzyme I with Inorganic Phosphate and Certain Other Anions. Nature 203:973-5.

Aragón JJ, Sánchez V. 1985. Enzyme concentration affects the allosteric behavior of yeast phosphofructokinase. Biochem Biophys Res Commun 131(2):849-55. 
Asadollahi MA, Maury J, Patil KR, Schalk M, Clark A, Nielsen J. 2009. Enhancing sesquiterpene production in Saccharomyces cerevisiae through in silico driven metabolic engineering. Metab Eng 11(6):328-34.

Asadollahi MA, Maury J, Schalk M, Clark A, Nielsen J. 2010. Enhancement of farnesyl diphosphate pool as direct precursor of sesquiterpenes through metabolic engineering of the mevalonate pathway in Saccharomyces cerevisiae. Biotechnol Bioeng 106(1):86-96.

Bailey JE, Sburlati A, Hatzimanikatis V, Lee K, Renner WA, Tsai PS. 2002. Inverse metabolic engineering: a strategy for directed genetic engineering of useful phenotypes. Biotechnol Bioeng 79(5):568-79.

Banta S, Boston M, Jarnagin A, Anderson S. 2002. Mathematical modeling of in vitro enzymatic production of 2-Keto-L-gulonic acid using $\mathrm{NAD}(\mathrm{H})$ or $\mathrm{NADP}(\mathrm{H})$ as cofactors. Metab Eng 4(4):273-84.

Bengtsson O, Jeppsson M, Sonderegger M, Parachin NS, Sauer U, Hahn-Hagerdal B, GorwaGrauslund MF. 2008. Identification of common traits in improved xylose-growing Saccharomyces cerevisiae for inverse metabolic engineering. Yeast 25(11):835-47.

Bettiga M, Gorwa-Grauslund MF, Hahn-Hägerdal B. 2010. Metabolic engineering in yeast. In: Smolke CD, editor. The metabolic pathway engineering handbook. Fundamentals. Boca Raton: CRC Press. p 1 - 48.

Brauer MJ, Huttenhower C, Airoldi EM, Rosenstein R, Matese JC, Gresham D, Boer VM, Troyanskaya OG, Botstein D. 2008. Coordination of growth rate, cell cycle, stress response, and metabolic activity in yeast. Mol Biol Cell 19(1):352-67.

Bro C, Knudsen S, Regenberg B, Olsson L, Nielsen J. 2005. Improvement of galactose uptake in Sacharomyces cerevisiae through overexpression of phosphoglucomutase: example of transcript analysis as a tool in inverse metabolic engineering. Appl Environ Microbiol 71(11):6465-72.

Bro C, Regenberg B, Förster J, Nielsen J. 2006. In silico aided metabolic engineering of Saccharomyces cerevisiae for improved bioethanol production. Metab Eng 8(2):102-11.

Buescher JM, Moco S, Sauer U, Zamboni N. 2010. Ultrahigh performance liquid chromatography-tandem mass spectrometry method for fast and robust quantification of anionic and aromatic metabolites. Anal Chem 82(11):4403-12.

Büscher JM, Czernik D, Ewald JC, Sauer U, Zamboni N. 2009. Cross-platform comparison of methods for quantitative metabolomics of primary metabolism. Anal Chem 81(6):2135-43.

Cakar ZP, Alkim C, Turanli B, Tokman N, Akman S, Sarikaya M, Tamerler C, Benbadis L, François JM. 2009. Isolation of cobalt hyper-resistant mutants of Saccharomyces cerevisiae by in vivo evolutionary engineering approach. J Biotechnol 143(2):130-8.

Cakar ZP, Seker UO, Tamerler C, Sonderegger M, Sauer U. 2005. Evolutionary engineering of multiple-stress resistant Saccharomyces cerevisiae. FEMS Yeast Res 5(6-7):569-78.

Canelas AB, Ras C, Ten Pierick A, van Dam JC, Heijnen JJ, van Gulik W. 2008a. Leakage-free rapid quenching technique for yeast metabolomics. Metabolomics 4:226-239.

Canelas AB, Ras C, ten Pierick A, van Gulik WM, Heijnen JJ. 2011. An in vivo data-driven framework for classification and quantification of enzyme kinetics and determination of apparent thermodynamic data. Metab Eng 13(3):294-306.

Canelas AB, ten Pierick A, Ras C, Seifar RM, van Dam JC, van Gulik WM, Heijnen JJ. 2009. Quantitative evaluation of intracellular metabolite extraction techniques for yeast metabolomics. Anal Chem 81(17):7379-89. 
Canelas AB, van Gulik WM, Heijnen JJ. 2008b. Determination of the cytosolic free NAD/NADH ratio in Saccharomyces cerevisiae under steady-state and highly dynamic conditions. Biotechnol Bioeng 100(4):734-43.

Castrillo JI, Oliver SG. 2005. Towards integrative functional genomics using yeast as a reference model. In: Vaidyanathan S, Harrigan GG, Goodacre R, editors. Metabolome analysis: Strategies for systems biology. Berlin: Springer-Verlag. p 9 30.

Castrillo JI, Oliver SG. 2006. Metabolomics and systems biology in Saccharomyces cerevisiae. In: Brown AJP, editor. Fungal Genomics. Berlin: Springer-Verlag. p 3 - 7.

Chaykin S. 1967. Nicotinamide coenzymes. Annu Rev Biochem 36:149-70.

Cipollina C, van den Brink J, Daran-Lapujade P, Pronk JT, Vai M, de Winde JH. 2008. Revisiting the role of yeast Sfp1 in ribosome biogenesis and cell size control: a chemostat study. Microbiology 154(Pt 1):337-46.

Ciriacy M, Breitenbach I. 1979. Physiological effects of seven different blocks in glycolysis in Saccharomyces cerevisiae. J Bacteriol 139(1):152-60.

Costenoble R, Adler L, Niklasson C, Lidén G. 2003. Engineering of the metabolism of Saccharomyces cerevisiae for anaerobic production of mannitol. FEMS Yeast Res 3(1):17-25.

Crabtree B, Newsholme EA, Reppas NB. 1997. Principles of regulation and control in biochemistry: a paradigmatic, flux-oriented approach. In: Hoffman JF, Jamieson JD, editors. Handbook of Physiology. New York, U.S.A.: Oxford University Press. p 117-180.

Crabtree HG. 1928. The carbohydrate metabolism of certain pathological overgrowths. Biochem J 22(5):1289-98.

Csuk R. 1991. Baker's yeast mediated transformations on organic chemistry. Chem Rev 91:49 $-97$.

Cvijovic M, Bordel S, Nielsen J. 2010. Mathematical models of cell factories: moving towards the core of industrial biotechnology. Microb Biotechnol 4(5):572-84.

de Koning W, van Dam K. 1992. A method for the determination of changes of glycolytic metabolites in yeast on a subsecond time scale using extraction at neutral $\mathrm{pH}$. Anal Biochem 204(1):118-23.

Dejong JM, Liu Y, Bollon AP, Long RM, Jennewein S, Williams D, Croteau RB. 2006. Genetic engineering of taxol biosynthetic genes in Saccharomyces cerevisiae. Biotechnol Bioeng 93(2):212-24.

den Hollander JA, Ugurbil K, Brown TR, Shulman RG. 1981. Phosphorus-31 nuclear magnetic resonance studies of the effect of oxygen upon glycolysis in yeast. Biochemistry 20(20):5871-80.

Devantier R, Scheithauer B, Villas-Bôas SG, Pedersen S, Olsson L. 2005. Metabolite profiling for analysis of yeast stress response during very high gravity ethanol fermentations. Biotechnol Bioeng 90(6):703-14.

Ding M-Z, Zhou X, Yuan Y-J. 2010. Metabolome profiling reveals adaptive evolution of Saccharomyces cerevisiae during repeated vacuum fermentations. Metabolomics 6:42 $-55$.

Dinh TN, Nagahisa K, Hirasawa T, Furusawa C, Shimizu H. 2008. Adaptation of Saccharomyces cerevisiae cells to high ethanol concentration and changes in fatty acid composition of membrane and cell size. PLoS One 3(7):e2623. 
Ditzelmüller G, Wöhrer W, Kubicek CP, Röhr M. 1983. Nucleotide pools of growing, synchronized and stressed cultures of Saccharomyces cerevisiae. Arch Microbiol 135(1):63-7.

Domingues L, Guimarães PM, Oliveira C. 2010. Metabolic engineering of Saccharomyces cerevisiae for lactose/whey fermentation. Bioeng Bugs 1(3):164-171.

Förster J, Famili I, Fu P, Palsson BØ, Nielsen J. 2003. Genome-scale reconstruction of the Saccharomyces cerevisiae metabolic network. Genome Res 13(2):244-53.

Garcia Sanchez R, Karhumaa K, Fonseca C, Sànchez Nogué V, Almeida JR, Larsson CU, Bengtsson O, Bettiga M, Hahn-Hägerdal B, Gorwa-Grauslund MF. 2010. Improved xylose and arabinose utilization by an industrial recombinant Saccharomyces cerevisiae strain using evolutionary engineering. Biotechnol Biofuels 3:13.

Gonzalez B, François J, Renaud M. 1997. A rapid and reliable method for metabolite extraction in yeast using boiling buffered ethanol. Yeast 13(14):1347-55.

Grosz R, Stephanopoulos G. 1990. Physiological, biochemical, and mathematical studies of micro-aerobic continuous ethanol fermentation by Saccharomyces cerevisiae. II: intracellular metabolite and enzyme assays at steady state chemostat cultures. Biotechnol Bioeng 36(10):1020-9.

Hasunuma T, Sanda T, Yamada R, Yoshimura K, Ishii J, Kondo A. 2011. Metabolic pathway engineering based on metabolomics confers acetic and formic acid tolerance to a recombinant xylose-fermenting strain of Saccharomyces cerevisiae. Microb Cell Fact 10(1):2.

Heinrich R, Rapoport TA. 1974. A linear steady-state treatment of enzymatic chains. General properties, control and effector strength. Eur J Biochem 42(1):89-95.

Hong ME, Lee KS, Yu BJ, Sung YJ, Park SM, Koo HM, Kweon DH, Park JC, Jin YS. 2010. Identification of gene targets eliciting improved alcohol tolerance in Saccharomyces cerevisiae through inverse metabolic engineering. J Biotechnol 149(1-2):52-9.

Hoppe A, Hoffmann S, Holzhutter HG. 2007. Including metabolite concentrations into flux balance analysis: thermodynamic realizability as a constraint on flux distributions in metabolic networks. BMC Syst Biol 1:23.

Hou J, Lages NF, Oldiges M, Vemuri GN. 2009. Metabolic impact of redox cofactor perturbations in Saccharomyces cerevisiae. Metab Eng 11(4-5):253-61.

Hult K, Berglund P. 2007. Enzyme promiscuity: mechanism and applications. Trends Biotechnol 25(5):231-8.

Ishida N, Saitoh S, Ohnishi T, Tokuhiro K, Nagamori E, Kitamoto K, Takahashi H. 2006. Metabolic engineering of Saccharomyces cerevisiae for efficient production of pure L(+)-lactic acid. Appl Biochem Biotechnol 129-132:795-807.

Jackson BE, Hart-Wells EA, Matsuda SP. 2003. Metabolic engineering to produce sesquiterpenes in yeast. Org Lett 5(10):1629-32.

Jeffries TW, Jin YS. 2004. Metabolic engineering for improved fermentation of pentoses by yeasts. Appl Microbiol Biotechnol 63(5):495-509.

Jin YS, Alper H, Yang YT, Stephanopoulos G. 2005. Improvement of xylose uptake and ethanol production in recombinant Saccharomyces cerevisiae through an inverse metabolic engineering approach. Appl Environ Microbiol 71(12):8249-56.

Johnston GC. 1977. Cell size and budding during starvation of the yeast Saccharomyces cerevisiae. J Bacteriol 132(2):738-9.

Johnston GC, Ehrhardt CW, Lorincz A, Carter BL. 1979. Regulation of cell size in the yeast Saccharomyces cerevisiae. J Bacteriol 137(1):1-5.

Kacser H, Burns JA. 1973. The control of flux. Symp Soc Exp Biol 27:65 - 104. 
Kahar P, Taku K, Tanaka S. 2011. Enhancement of xylose uptake in 2-deoxyglucose tolerant mutant of Saccharomyces cerevisiae. J Biosci Bioeng 111(5):557 - 563.

Kamei Y, Tamura T, Yoshida R, Ohta S, Fukusaki E, Mukai Y. 2011. GABA metabolism pathway genes, UGA1 and GAD1, regulate replicative lifespan in Saccharomyces cerevisiae. Biochem Biophys Res Commun 407(1):185-90.

Kjeldsen T. 2000. Yeast secretory expression of insulin precursors. Appl Microbiol Biotechnol 54(3):277-86.

Klimacek M, Krahulec S, Sauer U, Nidetzky B. 2010. Limitations in xylose-fermenting Saccharomyces cerevisiae, made evident through comprehensive metabolite profiling and thermodynamic analysis. Appl Environ Microbiol 76(22):7566-74.

Kötter P, Ciriacy M. 1993. Xylose fermentation by Saccharomyces cerevisiae. Appl Microbiol Biotechnol 38:776 - 783.

Krahulec S, Klimacek M, Nidetzky B. 2009. Engineering of a matched pair of xylose reductase and xylitol dehydrogenase for xylose fermentation by Saccharomyces cerevisiae. Biotechnol J 4(5):684-94.

Krahulec S, Klimacek M, Nidetzky B. 2011. Analysis and prediction of the physiological effects of altered coenzyme specificity in xylose reductase and xylitol dehydrogenase during xylose fermentation by Saccharomyces cerevisiae. J Biotechnol in press.

Krahulec S, Petschacher B, Wallner M, Longus K, Klimacek M, Nidetzky B. 2010. Fermentation of mixed glucose-xylose substrates by engineered strains of Saccharomyces cerevisiae: role of the coenzyme specificity of xylose reductase, and effect of glucose on xylose utilization. Microb Cell Fact 9:16.

Kubota S, Takeo I, Kume K, Kanai M, Shitamukai A, Mizunuma M, Miyakawa T, Shimoi H, Iefuji H, Hirata D. 2004. Effect of ethanol on cell growth of budding yeast: genes that are important for cell growth in the presence of ethanol. Biosci Biotechnol Biochem 68(4):968-72.

Kümmel A, Panke S, Heinemann M. 2006. Putative regulatory sites unraveled by networkembedded thermodynamic analysis of metabolome data. Mol Syst Biol 2:2006 0034 .

Kuroda S, Miyazaki T, Otaka S, Fujisawa Y. 1993. Saccharomyces cerevisiae can release hepatitis B virus surface antigen (HBsAg) particles into the medium by its secretory apparatus. Appl Microbiol Biotechnol 40(2-3):333-40.

Kuyper M, Toirkens MJ, Diderich JA, Winkler AA, van Dijken JP, Pronk JT. 2005. Evolutionary engineering of mixed-sugar utilization by a xylose-fermenting Saccharomyces cerevisiae strain. FEMS Yeast Res 5(10):925-34.

Lee KS, Hong ME, Jung SC, Ha SJ, Yu BJ, Koo HM, Park SM, Seo JH, Kweon DH, Park JC and others. 2010. Improved galactose fermentation of Saccharomyces cerevisiae through inverse metabolic engineering. Biotechnol Bioeng 108(3):621-31.

Lord PG, Wheals AE. 1981. Variability in individual cell cycles of Sacharomyces cerevisiae. J Cell Sci 50:361-76.

Lorincz A, Carter BL. 1979. Control of cell size at bud initiation in Saccharomyces cerevisiae. J Gen Microbiol 113:287 - 295.

Lowry OH, Passonneau JV, Rock MK. 1961. The stability of pyridine nucleotides. J Biol Chem 236:2756-9.

Lu W, Clasquin MF, Melamud E, Amador-Noguez D, Caudy AA, Rabinowitz JD. 2010. Metabolomic analysis via reversed-phase ion-pairing liquid chromatography coupled to a stand alone orbitrap mass spectrometer. Anal Chem 82(8):3212-21. 
MacKenzie DA, Defernez M, Dunn WB, Brown M, Fuller LJ, de Herrera SR, Günther A, James SA, Eagles J, Philo M and others. 2008. Relatedness of medically important strains of Saccharomyces cerevisiae as revealed by phylogenetics and metabolomics. Yeast 25(7):501-12.

Madsen KM, Udatha GD, Semba S, Otero JM, Koetter P, Nielsen J, Ebizuka Y, Kushiro T, Panagiotou G. 2011. Linking genotype and phenotype of Saccharomyces cerevisiae strains reveals metabolic engineering targets and leads to triterpene hyperproducers. PLoS One 6(3):e14763.

Mashego MR, Wu L, Van Dam JC, Ras C, Vinke JL, Van Winden WA, Van Gulik WM, Heijnen JJ. 2004. MIRACLE: mass isotopomer ratio analysis of U-13C-labeled extracts. A new method for accurate quantification of changes in concentrations of intracellular metabolites. Biotechnol Bioeng 85(6):620-8.

Mauch K, Vaseghi S, Reuss M. 2000. Quantitative analysis of metabolic signalling pathways in Saccharomyces cerevisiae. In: Schügerl K, Bellgardt KH, editors. Bioreaction engineering. Berlin: Springer Verlag. p 435 - 477.

Mountain HA, Sudbery PE. 1990. The relationship of growth rate and catabolite repression with WHI2 expression and cell size in Saccharomyces cerevisiae. J Gen Microbiol 136(4):733-7.

Mutka SC, Bondi SM, Carney JR, Da Silva NA, Kealey JT. 2006. Metabolic pathway engineering for complex polyketide biosynthesis in Saccharomyces cerevisiae. FEMS Yeast Res 6(1):40-7.

Navon G, Shulman RG, Yamane T, Eccleshall TR, Lam KB, Baronofsky JJ, Marmur J. 1979. Phosphorus-31 nuclear magnetic resonance studies of wild-type and glycolytic pathway mutants of Saccharomyces cerevisiae. Biochemistry 18(21):4487-99.

Nevoigt E. 2008. Progress in metabolic engineering of Saccharomyces cerevisiae. Microbiol Mol Biol Rev 72(3):379-412.

Nidetzky B, Helmer H, Klimacek M, Lunzer R, Mayer G. 2003. Characterization of recombinant xylitol dehydrogenase from Galactocandida mastotermitis expressed in Escherichia coli. Chem. Biol. Interact. 143-144:533-542.

Nielsen J. 2007. Metabolomics in functional genomics and systems biology. In: Villas-Bôas SG, Roessner U, Hansen MAE, Smedsgaard J, Nielsen J, editors. Metabolome analysis: An Introduction. Hoboken: John Wiley \& Sons, Inc. p 3 - 14.

Nielsen J, Jewett MC. 2008. Impact of systems biology on metabolic engineering of Saccharomyces cerevisiae. FEMS Yeast Res 8(1):122-31.

Nissen TL, Hamann CW, Kielland-Brandt MC, Nielsen J, Villadsen J. 2000a. Anaerobic and aerobic batch cultivations of Saccharomyces cerevisiae mutants impaired in glycerol synthesis. Yeast 16(5):463-74.

Nissen TL, Kielland-Brandt MC, Nielsen J, Villadsen J. 2000b. Optimization of ethanol production in Saccharomyces cerevisiae by metabolic engineering of the ammonium assimilation. Metab Eng 2(1):69-77.

Parachin NS, Bergdahl B, van Niel EW, Gorwa-Grauslund MF. 2011. Kinetic modelling reveals current limitations in the production of ethanol from xylose by recombinant Saccharomyces cerevisiae. Metab Eng in press.

Pereira FB, Guimarães PMR, Teixeira JA, Domingues L. 2011. Robust industrial Saccharomyces cerevisiae strains for very high gravity bio-ethanol fermentations. J Biosci Bioeng 112(2):130 - 136.

Petschacher B, Leitgeb S, Kavanagh KL, Wilson DK, Nidetzky B. 2005. The coenzyme specificity of Candida tenuis xylose reductase (AKR2B5) explored by site-directed mutagenesis and X-ray crystallography. Biochem. J. 385(Pt 1):75-83. 
Petschacher B, Nidetzky B. 2005. Engineering Candida tenuis Xylose reductase for improved utilization of NADH: antagonistic effects of multiple side chain replacements and performance of site-directed mutants under simulated in vivo conditions. Appl. Environ. Microbiol. 71(10):6390-6393.

Petschacher B, Nidetzky B. 2008. Altering the coenzyme preference of xylose reductase to favor utilization of NADH enhances ethanol yield from xylose in a metabolically engineered strain of Saccharomyces cerevisiae. Microb Cell Fact 7:9.

Pirkov I, Albers E, Norbeck J, Larsson C. 2008. Ethylene production by metabolic engineering of the yeast Saccharomyces cerevisiae. Metab Eng 10(5):276-80.

Porro D, Brambilla L, Alberghina L. 2003. Glucose metabolism and cell size in continuous cultures of Saccharomyces cerevisiae. FEMS Microbiol Lett 229(2):165-71.

Raab AM, Gebhardt G, Bolotina N, Weuster-Botz D, Lang C. 2010. Metabolic engineering of Saccharomyces cerevisiae for the biotechnological production of succinic acid. Metab Eng 12(6):518-25.

Raamsdonk LM, Teusink B, Broadhurst D, Zhang N, Hayes A, Walsh MC, Berden JA, Brindle KM, Kell DB, Rowland JJ and others. 2001. A functional genomics strategy that uses metabolome data to reveal the phenotype of silent mutations. Nat Biotechnol 19(1):45-50.

Racker E. 1974. History of the Pasteur effect and its pathobiology. Mol Cell Biochem 5(12):17-23.

Ralser M, Wamelink MM, Kowald A, Gerisch B, Heeren G, Struys EA, Klipp E, Jakobs C, Breitenbach M, Lehrach $\mathrm{H}$ and others. 2007. Dynamic rerouting of the carbohydrate flux is key to counteracting oxidative stress. J Biol 6(4):10.

Reuss M, Aguilera-Vázques L, Mauch K. 2007. Reconstruction of dynamic network models from metabolite measurements. In: Nielsen J, Jewett MC, editors. Metabolomics. Berlin: Springer-Verlag. p 97 - 127.

Rizzi M, Baltes M, Theobald U, Reuss M. 1997. In vivo analysis of metabolic dynamics in Saccharomyces cerevisiae: II. Mathematical model. Biotechnol Bioeng 55(4):592-608.

Rocha I, Maia P, Evangelista P, Vilaca P, Soares S, Pinto JP, Nielsen J, Patil KR, Ferreira EC, Rocha M. OptFlux: an open-source software platform for in silico metabolic engineering. BMC Syst Biol 4:45.

Segel IH. 1993. Enzyme Kinetics - Behavior and analysis of rapid equilibrium and steadystate enzyme systems. New York: Wiley interscience.

Selvarajoo K, Arjunan SNV, Tomita M. 2010. In silico models for metabolic systems engineering. In: Smolke CD, editor. The metabolic pathway engineering handbook. Tools and applications. Boca Raton: CRC Press. p 1 - 22.

Shanks JV, Bailey JE. 1988. Estimation of intracellular sugar phosphate concentrations in Saccharomyces cerevisiae using $31 \mathrm{P}$ nuclear magnetic resonance spectroscopy. Biotechnol Bioeng 32(9):1138-52.

Sonderegger M, Sauer U. 2003. Evolutionary engineering of Saccharomyces cerevisiae for anaerobic growth on xylose. Appl Environ Microbiol 69(4):1990-8.

Steen EJ, Chan R, Prasad N, Myers S, Petzold CJ, Redding A, Ouellet M, Keasling JD. 2008. Metabolic engineering of Saccharomyces cerevisiae for the production of n-butanol. Microb Cell Fact 7:36.

Steinle A, Bergander K, Steinbüchel A. 2009. Metabolic engineering of Saccharomyces cerevisiae for production of novel cyanophycins with an extended range of constituent amino acids. Appl Environ Microbiol 75(11):3437-46. 
Stephanopoulos GN, Aristidou A, Nielsen J. 1998. Metabolic engineering, principles and methodologies. San Diego: Academic Press.

Tamaki H, Yun CW, Mizutani T, Tsuzuki T, Takagi Y, Shinozaki M, Kodama Y, Shirahige K, Kumagai H. 2005. Glucose-dependent cell size is regulated by a $G$ protein-coupled receptor system in yeast Saccharomyces cerevisiae. Genes Cells 10(3):193-206.

Theobald U, Mailinger W, Baltes M, Rizzi M, Reuss M. 1997. In vivo analysis of metabolic dynamics in Saccharomyces cerevisiae : I. Experimental observations. Biotechnol Bioeng 55(2):305-16.

Thorsen M, Lagniel G, Kristiansson E, Junot C, Nerman O, Labarre J, Tamás MJ. 2007. Quantitative transcriptome, proteome, and sulfur metabolite profiling of the Saccharomyces cerevisiae response to arsenite. Physiol Genomics 30(1):35-43.

Toivari MH, Ruohonen L, Miasnikov AN, Richard P, Penttilä M. 2007. Metabolic engineering of Sacharomyces cerevisiae for conversion of D-glucose to xylitol and other five-carbon sugars and sugar alcohols. Appl Environ Microbiol 73(17):5471-6.

Trantas E, Panopoulos N, Ververidis F. 2009. Metabolic engineering of the complete pathway leading to heterologous biosynthesis of various flavonoids and stilbenoids in Saccharomyces cerevisiae. Metab Eng 11(6):355-66.

Tyson CB, Lord PG, Wheals AE. 1979. Dependency of size of Saccharomyces cerevisiae cells on growth rate. J Bacteriol 138(1):92-8.

Ukibe K, Hashida K, Yoshida N, Takagi H. 2009. Metabolic engineering of Saccharomyces cerevisiae for astaxanthin production and oxidative stress tolerance. Appl Environ Microbiol 75(22):7205-11.

Usaite R, Jewett MC, Oliveira AP, Yates JR, 3rd, Olsson L, Nielsen J. 2009. Reconstruction of the yeast Snf1 kinase regulatory network reveals its role as a global energy regulator. Mol Syst Biol 5:319.

van Eunen K, Bouwman J, Daran-Lapujade P, Postmus J, Canelas AB, Mensonides FI, Orij R, Tuzun I, van den Brink J, Smits GJ and others. 2010. Measuring enzyme activities under standardized in vivo-like conditions for systems biology. Febs J 277(3):74960.

van Eunen K, Bouwman J, Lindenbergh A, Westerhoff HV, Bakker BM. 2009. Timedependent regulation analysis dissects shifts between metabolic and geneexpression regulation during nitrogen starvation in baker's yeast. Febs J 276(19):5521-36.

van Gulik WM. 2010. Fast sampling for quantitative microbial metabolomics. Curr Opin Biotechnol 21(1):27-34.

van Maris AJ, Winkler AA, Kuyper M, de Laat WT, van Dijken JP, Pronk JT. 2007. Development of efficient xylose fermentation in Saccharomyces cerevisiae: xylose isomerase as a key component. Adv Biochem Eng Biotechnol 108:179-204.

Villas-Bôas SG. 2007a. Microbial metabolomics: Rapid sampling techniques to investigate intracellular metabolite dynamics - an overview. In: Villas-Bôas SG, Roessner U, Hansen MAE, Smedsgaard J, Nielsen J, editors. Metabolome analysis: An introduction: John Wiley \& Sons, Inc. p 203 - 214.

Villas-Bôas SG. 2007b. Sampling and sample preparation. In: Villas-Bôas SG, Roessner U, Hansen MAE, Smedsgaard J, Nielsen J, editors. Metabolome analysis: An introduction: John Wiley \& Sons, Inc. p 39 - 82.

Villas-Bôas SG, Åkesson M, Nielsen J. 2005a. Biosynthesis of glyoxylate from glycine in Saccharomyces cerevisiae. FEMS Yeast Res 5(8):703-9. 
Villas-Bôas SG, Bruheim P. 2007. Cold glycerol-saline: the promising quenching solution for accurate intracellular metabolite analysis of microbial cells. Anal Biochem 370(1):87-97.

Villas-Bôas SG, Delicado DG, Åkesson M, Nielsen J. 2003. Simultaneous analysis of amino and nonamino organic acids as methyl chloroformate derivatives using gas chromatography-mass spectrometry. Anal Biochem 322(1):134-8.

Villas-Bôas SG, Hojer-Pedersen J, Åkesson M, Smedsgaard J, Nielsen J. 2005b. Global metabolite analysis of yeast: evaluation of sample preparation methods. Yeast 22(14):1155-69.

Villas-Bôas SG, Moxley JF, Åkesson M, Stephanopoulos G, Nielsen J. 2005c. Highthroughput metabolic state analysis: the missing link in integrated functional genomics of yeasts. Biochem J 388(Pt 2):669-77.

Visser D, Heijnen JJ. 2002. The mathematics of metabolic control analysis revisited. Metab Eng 4(2):114-23.

Visser D, Heijnen JJ. 2003. Dynamic simulation and metabolic re-design of a branched pathway using linlog kinetics. Metab Eng 5(3):164-76.

Visser W, Scheffers WA, Batenburg-van der Vegte WH, van Dijken JP. 1990. Oxygen requirements of yeasts. Appl Environ Microbiol 56(12):3785-92.

Wang L, Birol I, Hatzimanikatis V. 2004. Metabolic control analysis under uncertainty: framework development and case studies. Biophys J 87(6):3750-63.

Wisselink HW, Cipollina C, Oud B, Crimi B, Heijnen JJ, Pronk JT, van Maris AJ. 2010. Metabolome, transcriptome and metabolic flux analysis of arabinose fermentation by engineered Saccharomyces cerevisiae. Metab Eng 12(6):537-51.

Wisselink HW, Toirkens MJ, del Rosario Franco Berriel M, Winkler AA, van Dijken JP, Pronk JT, van Maris AJ. 2007. Engineering of Saccharomyces cerevisiae for efficient anaerobic alcoholic fermentation of L-arabinose. Appl Environ Microbiol 73(15):4881-91.

Wisselink HW, Toirkens MJ, Wu Q, Pronk JT, van Maris AJ. 2009. Novel evolutionary engineering approach for accelerated utilization of glucose, xylose, and arabinose mixtures by engineered Saccharomyces cerevisiae strains. Appl Environ Microbiol 75(4):907-14.

Wu L, Mashego MR, van Dam JC, Proell AM, Vinke JL, Ras C, van Winden WA, van Gulik WM, Heijnen JJ. 2005. Quantitative analysis of the microbial metabolome by isotope dilution mass spectrometry using uniformly 13C-labeled cell extracts as internal standards. Anal Biochem 336(2):164-71.

Wu L, Wang W, van Winden WA, van Gulik WM, Heijnen JJ. 2004. A new framework for the estimation of control parameters in metabolic pathways using lin-log kinetics. Eur J Biochem 271(16):3348-59.

Yoshida S, Imoto J, Minato T, Oouchi R, Sugihara M, Imai T, Ishiguro T, Mizutani S, Tomita M, Soga $\mathrm{T}$ and others. 2008. Development of bottom-fermenting Saccharomyces strains that produce high $\mathrm{SO}_{2}$ levels, using integrated metabolome and transcriptome analysis. Appl Environ Microbiol 74(9):2787-96.

Zaldivar J, Borges A, Johansson B, Smits HP, Villas-Boas SG, Nielsen J, Olsson L. 2002. Fermentation performance and intracellular metabolite patterns in laboratory and industrial xylose-fermenting Saccharomyces cerevisiae. Appl Microbiol Biotechnol 59(4-5):436-42.

Zamboni N, Kümmel A, Heinemann M. 2008. anNET: a tool for network-embedded thermodynamic analysis of quantitative metabolome data. BMC Bioinformatics 9:199. 


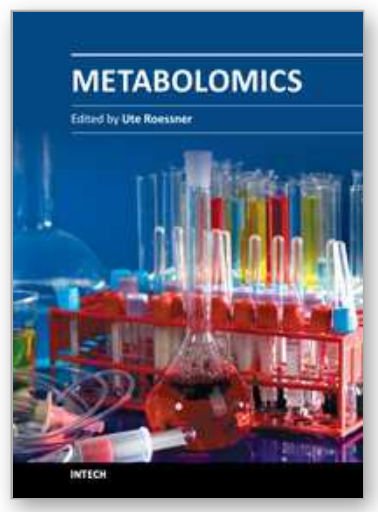

\author{
Metabolomics \\ Edited by Dr Ute Roessner
}

ISBN 978-953-51-0046-1

Hard cover, 364 pages

Publisher InTech

Published online 10, February, 2012

Published in print edition February, 2012

Metabolomics is a rapidly emerging field in life sciences, which aims to identify and quantify metabolites in a biological system. Analytical chemistry is combined with sophisticated informatics and statistics tools to determine and understand metabolic changes upon genetic or environmental perturbations. Together with other 'omics analyses, such as genomics and proteomics, metabolomics plays an important role in functional genomics and systems biology studies in any biological science. This book will provide the reader with summaries of the state-of-the-art of technologies and methodologies, especially in the data analysis and interpretation approaches, as well as give insights into exciting applications of metabolomics in human health studies, safety assessments, and plant and microbial research.

\title{
How to reference
}

In order to correctly reference this scholarly work, feel free to copy and paste the following:

Mario Klimacek (2012). Quantitative Metabolomics and Its Application in Metabolic Engineering of Microbial Cell Factories Exemplified by the Baker's Yeast, Metabolomics, Dr Ute Roessner (Ed.), ISBN: 978-953-510046-1, InTech, Available from: http://www.intechopen.com/books/metabolomics/quantitative-metabolomicsand-its-application-in-metabolic-engineering-of-microbial-cell-factories-e

\section{INTECH}

open science | open minds

InTech Europe

University Campus STeP Ri

Slavka Krautzeka 83/A

51000 Rijeka, Croatia

Phone: +385 (51) 770447

Fax: +385 (51) 686166

www.intechopen.com
InTech China

Unit 405, Office Block, Hotel Equatorial Shanghai

No.65, Yan An Road (West), Shanghai, 200040, China

中国上海市延安西路65号上海国际贵都大饭店办公楼405单元

Phone: +86-21-62489820

Fax: +86-21-62489821 
(C) 2012 The Author(s). Licensee IntechOpen. This is an open access article distributed under the terms of the Creative Commons Attribution 3.0 License, which permits unrestricted use, distribution, and reproduction in any medium, provided the original work is properly cited. 